\title{
Comportamento e preferência alimentar de éguas da raça Mangalarga Marchador alimentadas com silagens de milho, sorgo e hermártria
}

\author{
Behavior and food preference of Mangalarga Marchador mares \\ fed with maize, sorghum and limpograss silages
}

Helen Aline Melo ${ }^{[a]}$,João Ricardo Dittrich ${ }^{[b]}$, Dayana Swaroski[ ${ }^{[c]}$, Gabriela Bettega Moressi[c], Rafael Salles Cabreira ${ }^{[c]}$, Tatiana Louise Gazda $^{[\mathrm{d}]}$,Alda Lúcia Gomes Monteiro ${ }^{[\mathrm{e}]}$,Simone Gisele de Oliveira ${ }^{[\mathrm{e}]}$, Rosangela Locatelli Dittrich ${ }^{[\mathrm{f}]}$,Ana Luisa Palhano Silva ${ }^{[9]}$

\footnotetext{
[a] Médica-Veterinária, mestre em Ciências Veterinárias pela Universidade Federal do Paraná (UFPR), Programa de PósGraduação em Ciências Veterinárias, Curitiba, PR - Brasil, e-mail: helen_alinemelo@hotmail.com

[b] Professor doutor do Departamento de Zootecnia da Universidade Federal do Paraná (UFPR), Curitiba, PR - Brasil, e-mail: dittrich@ufpr.br

[c] Estudantes de Medicina Veterinária e Zootecnia na Universidade Federal do Paraná (UFPR), Curitiba, PR - Brasil.

[d] Médica-Veterinária, doutoranda em Processos Biotecnológicos na Universidade Federal do Paraná (UFPR), Curitiba, PR - Brasil.

[e] Professoras doutoras do Departamento de Zootecnia da Universidade Federal do Paraná (UFPR), Curitiba, PR - Brasil.

[f] Professora doutora do Departamento de Medicina Veterinária da Universidade Federal do Paraná (UFPR), Curitiba, PR Brasil, e-mail: roslocdi@ufpr.br

[g] Professora doutora da Universidade Tuiuti do Paraná (UTP), Curitiba, PR - Brasil, e-mail: a.luisa@pop.com.br
}

\section{Resumo}

Este trabalho objetivou avaliar o comportamento alimentar de éguas Mangalarga Marchador alimentadas com silagens de milho (SM), sorgo (SS) e hemártria com melaço e fubá (SH). 0 trabalho foi composto de dois ensaios. No primeiro, seis éguas foram alimentadas em duplas com uma das três silagens por nove dias em quadrado latino ( $3 \times 3$ ). No segundo, as éguas tiveram livre acesso às silagens fornecidas em recipiente próprio por duas horas em dois dias. 0 consumo (MS/100 kg PV) foi de 1,74\% para SM, 1,90\% SS e 3,06\% SH. O tempo de consumo entre SM, SS e SH foi semelhante no primeiro ensaio $(p>0,05)$; $9 \mathrm{~h}, 10 \mathrm{~h} 16$ e $10 \mathrm{~h}$ para SM, SS e SH, respectivamente. A ingestão de SH foi maior $(\mathrm{p}<0,05)$ em função do tamanho da partícula e da adição de melaço. No segundo ensaio, o tempo de ingestão das silagens foi de $32,16 \%$ (SM), 11,66\% (SS) e 56,18\% (SH). 0 tempo destinado à ingestão diária de silagem pelos equinos foi semelhante no dia e entre períodos de avaliação, diurnos e noturnos, independentemente do tamanho da partícula, do conteúdo energético e da composição química das silagens. Éguas da raça Mangalarga Marchador preferem e consomem maiores quantidades de silagens com partículas de menor tamanho e confeccionadas com melaço.

Palavras-chave: Silagem. Preferência. Consumo. Mangalarga Marchador. 


\section{Abstract}

The aim of this study was to evaluate the diet behavior of Mangalarga Marchador mares fed with maize silage (MS), sorghum silage (SS) or limpograss silage mixed with molasses and cornmeal (LS). Two experiments were conducted during this work. Firstly, six mares were fed in pairs with one of the three silages for nine days using Latin square $(3 \times 3)$ for randomization. Secondly, mares had free access to the silage for two days during two hours in each day. The feed consumption (DM/100 kg LW) was 1.74\% for SM, 1.90\% SS and 3.06\% SH. The consumption period for all diets was similar during the first test: 9, 10:16 and 10 a.m to MS, SS and LS, respectively. The larger consumption of SH was facilitated by its particle size and the presence of molasses in this feed. The time-share spent for the ingestion of each silage-based feed during the second experiment was: 32.16\% for SM, $11.66 \%$ for SS and $56.18 \%$ for SH. The time spent on feed consumption by the mares was similar throughout this study. The smaller particle size and the presence of molasses in the silage were considered important factors to increase the time spent eating and the quantity consumed by the Mangalarga Marchador mares.

Keywords: Silage. Preference. Consumption. Mangalarga Marchador.

\section{Introdução}

O oferecimento de forragens para equinos, segundo Lewis (2000), pode ocorrer de várias formas: pastejo, fornecimento de feno, forragem verde picada e silagem. 0 pastejo direto é a forma que, na maioria das vezes, respeita mais a fisiologia digestiva dos herbívoros; porém, em virtude da estacionalidade da produção, são necessários, muitas vezes, meios alternativos para a alimentação animal.

A utilização do feno para a alimentação dos cavalos é amplamente difundida, mas a utilização de silagem vem despertando o interesse de muitos criadores e técnicos, pois é a forma de conservação de forragens mais independente das condições climáticas no momento do seu processamento (MÜLBACH, 1999). A utilização de silagens na alimentação equina é comum em países europeus (HANCHE-OLSEN et al., 2008). No Brasil ocorre principalmente pela aproximação dos cavalos aos ambientes alimentares de bovinos (DOMINGUES, 2009).

Müller e Udén (2007), avaliando a preferência de equinos de raças distintas entre uma silagem, dois pré-secados e um feno, observaram que esses animais preferiam a silagem aos outros alimentos.

Poucos são os trabalhos científicos a respeito do uso de silagem na alimentação de equinos. A utilização de silagens de grãos úmidos vem sendo estudada por alguns autores como forma de fornecimento de alimento concentrado. Santos et al. (2002), avaliando a utilização de silagem de grãos úmidos para equinos em crescimento, obteve bons resultados quanto à aceitabilidade e digestibilidade do alimento. Oliveira et al. (2007) também obtiveram bons resultados referentes à digestibilidade na utilização de silagem de grãos úmidos de triticale para equinos, semelhantes aos encontrados por Santos et al. (2002).

Em razão da carência de informações científicas a respeito da utilização de silagens na alimentação de cavalos, este trabalho objetivou identificar as características comportamentais de éguas alimentadas exclusivamente com três tipos de silagens.

\section{Materiais e métodos}

O experimento foi realizado em um haras, com equinos da raça Mangalarga Marchador, localizado no município de Piraquara (PR), em junho e julho de 2007, apresentando clima Cfb de acordo com a classificação de Köppen (1901).

No estudo foram utilizadas seis éguas não prenhes da raça Mangalarga Marchador, com 2 a 3 anos de idade e peso médio de $265 \mathrm{~kg}$. Os animais foram submetidos a exames clínicos de auscultação cardíaca e respiratória, mensuração de temperatura retal, tempo de preenchimento capilar na mucosa oral e exame coproparasitológico, aos 15 e aos 7 dias antes do período experimental. Os animais foram vermifugados previamente ao estudo, com Ivermectina oral $\left(0,2 \mathrm{mg} \cdot \mathrm{kg}^{-1}\right)$.

As silagens utilizadas foram: silagem de milho (Zeamais)-SM, silagem de sorgo (Sorghumvulgare)- 
SS e silagem de hemártria (Hermathria altissima) SH. As plantas de milho e sorgo ensiladas estavam em estágio final produtivo e apresentavam grãos com textura farinácea. A hemártria foi pré-secada e no momento da ensilagem foram adicionados $2,5 \%$ de melaço em pó e $5 \%$ de fubá amarelo, objetivando melhor fermentação e conservação do alimento. Houve colheitas de material para as análises qualitativas dos alimentos no momento de abertura de cada silo. Essas amostras passaram por análise química em forma de duplicata, sendo a análise repetida caso as amostras apresentassem valores com variação superior a $10 \%$. Os alimentos foram analisados no Laboratório de Nutrição Animal da UFPR, utilizando-se os métodos descritos pela AOAC (1995) para avaliar matéria seca (MS), proteína bruta (PB), extrato etéreo (EE), cálcio (Ca) e fósforo (P). Além disso, realizou-se o método descrito por Van Soest (1994) para determinação de fibra em detergente neutro (FDN) e fibra em detergente ácido (FDA). As silagens foram submetidas à determinação de $\mathrm{pH}$ por meio de potenciômetro digital e nitrogênio amoniacal pelo método colorimétrico exposto por Chaney e Marbach (1962) (Tabela 1).

Além da avaliação química, as características físicas das silagens foram avaliadas por meio da passagem das amostras, secas em estufa por 72 horas a $36^{\circ} \mathrm{C}$, por três peneiras retangulares a fim de se determinar o tamanho das partículas que as compunham. As malhas nas três peneiras utilizadas eram de $3,5 \mathrm{~cm}$, $2 \mathrm{~cm} \mathrm{e} 0,5 \mathrm{~cm}$, passadas da peneira com maior malha para a de menor malha, por meio de dez movimentos da peneira, repetidos quatro vezes em cada. Esse procedimento foi adaptação do método descrito por Lammes et al. (1996). As características físicas das silagens estão apresentadas na Tabela 2.

No período pré-experimental (nove dias), os animais receberam as três silagens como forma de adaptação à nova dieta. 0 período experimental foi dividido em dois ensaios. No primeiro, de 21 de junho a 17 de julho de 2007, os animais permaneceram alocados dois a dois em baias de tamanho médio de 103,32 $\mathrm{m}^{2}$. Em cada baia fez-se o fornecimento ad libitum de um tipo diferente das três silagens em cada ciclo de avaliação. Os animais foram pesados antes e após cada período experimental, decorridas 12 horas de jejum. 0 fornecimento da silagem foi dividido em seis vezes ao dia, de modo a não faltar alimento aos animais.
No último dia de cada ciclo de avaliação, o comportamento ingestivo foi avaliado por observação visual dos animais no período de 24 horas ininterruptas. A cada 10 minutos, de forma pontual, anotou-se em folha própria de avaliação se o animal estava se alimentando ou não (MARTIN; BATESON, 1986). Considerou-se consumo diurno entre as 6:00 da manhã e 6:00 da tarde, e consumo noturno entre as 6:00 da tarde e 6:00 da manhã seguinte.

0 consumo (kg de MS para $100 \mathrm{~kg}$ de massa corporal) das silagens foi obtido subtraindo-se a quantidade inicial das sobras após 24 horas de avaliação, descontada a umidade do alimento.

Após o término dos nove dias, os animais permaneceram em jejum alimentar e hídrico, por 12 horas. Eles eram pesados em balança digital própria, alocados em outra acomodação e era oferecido outro tipo de silagem. No primeiro ensaio, o delineamento experimental foi quadrado latino $3 \times 3$ (três silagens e três períodos).

O segundo ensaio iniciou-se dois dias após o fim do primeiro, com o objetivo de identificar a preferência alimentar dos animais entre as três silagens. Seis recipientes plásticos com abertura circular de $39 \mathrm{~cm}$ de diâmetro e capacidade de 15 litros, contendo $1 \mathrm{~kg}$ de matéria seca de cada silagem, foram utilizados. Dois recipientes continham SM, dois, SS e dois, SH. 0 período de avaliação foi de duas horas, sendo uma hora no período da manhã e uma no período da tarde.

As características de preferência avaliadas foram: a primeira escolha, o tempo de consumo de cada tipo de silagem e o percentual consumido ao final do período avaliado, sempre de forma inteiramente casualizada.

Para a análise estatística dos dois ensaios, utilizou-se o programa STATISTICA, versão 5.5. Após análise da variância (ANOVA), as médias foram testadas a $5 \%$ de probabilidade empregando-se o teste de Tukey.

\section{Resultados e discussão}

As características químicas e físicas das silagens utilizadas e a estimativa de energia digestível estão apresentadas nas Tabelas 1 e 2. Na avaliação do comportamento alimentar identificou-se que o tempo diário de consumo, em 24 horas, foi semelhante entre os três tipos de silagem ( $p>0,05)$. 
Tabela 1 - Composição bromatológica, energia digestível estimada, pH e nitrogênio amoniacal das silagens de milho (SM), sorgo (SS) e hemártria (SH) utilizadas no experimento

\begin{tabular}{|c|c|c|c|c|c|c|c|c|c|c|c|c|}
\hline & $\begin{array}{l}\text { M.S. } \\
(\%)\end{array}$ & $\begin{array}{l}\text { P.B. } \\
\text { (\%) }\end{array}$ & $\begin{array}{l}\text { F.D.A. } \\
\text { (\%) }\end{array}$ & $\begin{array}{l}\text { F.D.N. } \\
(\%)\end{array}$ & $\begin{array}{l}\text { E.E. } \\
\text { (\%) }\end{array}$ & $\begin{array}{c}\text { E.N.N. } \\
(\%)\end{array}$ & $\begin{array}{l}\text { R.M. } \\
\text { (\%) }\end{array}$ & $\begin{array}{l}\mathrm{Ca} \\
(\%)\end{array}$ & $\begin{array}{c}P \\
(\%)\end{array}$ & $\mathrm{pH}$ & $\begin{array}{l}\text { E.D. } \\
\text { (Mcal/kg MS)* }^{*}\end{array}$ & $\begin{array}{l}\text { Nitrogênio } \\
\text { Amoniacal (\%) }\end{array}$ \\
\hline \multirow[t]{2}{*}{ SM } & $35,1^{b}$ & $7,04^{a}$ & 40,35 & 72,20 & $4,02^{\mathrm{a}}$ & $53,48^{b}$ & 2,99 & 0,18 & 0,15 & 4,0 & $2,68^{a}$ & 0,12 \\
\hline & & & & & & & & & & 7 & & \\
\hline \multirow[t]{2}{*}{ SS } & $33,7^{c}$ & $6,75^{\mathrm{a}}$ & 41,60 & 68,91 & $4,06^{\mathrm{a}}$ & $52,88^{b}$ & 4,25 & 0,22 & 0,16 & 4,0 & $2,73^{a}$ & 0,09 \\
\hline & & & & & & & & & & 1 & & \\
\hline \multirow[t]{2}{*}{ SH } & $59,3^{\text {a }}$ & $4,00^{b}$ & 38,93 & 83,10 & $2,29^{\mathrm{ab}}$ & $57,99^{a}$ & 4,07 & 0,20 & 0,11 & 4,0 & $2,19^{b}$ & 0,10 \\
\hline & & & & & & & & & & 1 & & \\
\hline
\end{tabular}

Fonte: Dados da pesquisa.

Legenda: M.S. = matéria seca; F.B. = fibra bruta; P.B. = proteína bruta; F.D.A. = fibra em detergente ácido; F.D.N. = fibra em detergente neutro; E.E. = estrato etéreo; E.N.N = extrativo não nitrogenado; R.M. = resíduo mineral; $\mathrm{Ca}$ = cálcio; P = fósforo; E. D. = energia digestível estimada pela fórmula descrita por Pagan et al. (1998). Letras distintas nas colunas representam diferença pelo teste de Tukey $(p<0,05)$.

Tabela 2 - Caracterização física das silagens de milho, sorgo e hemártria fornecidas às éguas da raça Mangalarga Marchador

\begin{tabular}{lcccc}
\hline & $\begin{array}{c}\text { Partículas } \\
\text { menores que } \mathbf{0 , 5} \mathbf{~ c m} \\
\text { Silagens }\end{array}$ & $\begin{array}{c}\text { Partículas } \\
\text { entre } \mathbf{0 , 5}-\mathbf{~ c m} \\
\mathbf{( \% )}\end{array}$ & $\begin{array}{c}\text { Partículas } \\
\text { entre 2-3,5 cm } \\
\text { (\%) }\end{array}$ & $\begin{array}{c}\text { Partículas } \\
\text { maiores que 3,5 cm } \\
\text { (\%) }\end{array}$ \\
\hline Milho & 28,44 & 50,10 & 11,16 & 10,29 \\
Sorgo & 55,97 & 32,35 & 4,83 & 6,84 \\
Hemártria & 44,09 & 49,10 & 6,00 & 0,81 \\
\hline
\end{tabular}

Fonte: Dados da pesquisa.

O tempo de consumo diurno e noturno foi semelhante para os três tipos de silagem $(p>0,05)$ (Tabela 3). 0 tempo utilizado pelos animais para a ingestão das silagens foi maior durante o dia, quando comparado com o consumo noturno. 0 tempo encontrado para o consumo noturno foi equivalente a aproximadamente a metade do tempo do consumo diurno. 0 consumo diurno representou $67,04 \%$; $62,13 \%$ e $66 \%$ do tempo do consumo gasto pelos animais para as silagens de milho, sorgo e hemártria, respectivamente (Tabela 3). Maior tempo de ingestão no período diurno também foi identificado com equinos em pastejo, independentemente das condições climáticas ou da raça dos cavalos utilizados (SANTOS et al., 2006). A ingestão de alimentos no período noturno pelos cavalos, apesar de menor, ocorreu independente da forma em que o alimento volumoso foi oferecido.
O consumo diário de silagem (\% massa corporal em matéria seca) foi de 1,74\%,1,90\% e 3,06\% para os animais alimentados com silagem de milho, sorgo e hemártria, respectivamente. Os valores encontrados para as silagens de milho e de sorgo estiveram muito próximos dos encontrados por Morrow et al. (1999), Moore-Colyer e Longland (2000) e Bergero et al. (2002), os quais avaliaram o consumo de silagens de gramíneas forrageiras por pôneis, e obtiveram valores entre 1,47\% e 2,2\%. Em revisão apresentada pelo National Research Council - NRC (2007), observa-se que a silagem de milho apresenta menor consumo voluntário, comparativamente a alguns tipos de silagens e de fenos. 0 percentual de consumo da SH foi maior $(p<0,05)$, o que pode sugerir preferência dos animais por tal silagem. As três silagens utilizadas neste experimento apresentaram o mesmo conteúdo de energia digestível 
Tabela 3 - Consumo alimentar diuturno de éguas da raça Mangalarga Marchador alimentadas com três tipos de silagem

\begin{tabular}{lcccc}
\hline Silagem & \multicolumn{2}{l}{$\begin{array}{l}\text { Tempo de consumo diurno } \\
\text { (horas) }\end{array}$} & $\begin{array}{l}\text { Tempo de consumo noturno } \\
\text { (horas) }\end{array}$ & $\begin{array}{l}\text { Tempo diário de consumo } \\
\text { (horas) }\end{array}$ \\
\hline Milho & $5,9^{\mathrm{a}}$ & $2,9^{\mathrm{b}}$ & 8,8 \\
Sorgo & $6,4^{\mathrm{a}}$ & $3,9^{\circ}$ & 10,3 \\
Hemártria & $6,6^{\mathrm{a}}$ & $3,3^{\mathrm{b}}$ & 9,9 \\
\hline Coeficiente de Variação (\%) & 16,35 & 24,91 & 15,84 \\
\hline
\end{tabular}

Fonte: Dados da pesquisa.

Legenda: ${ }^{a} \mathrm{p}<0,05 \mathrm{vs}^{\mathrm{b}}$.

(E.D. Mcal/kg), mas a ingestão diária foi maior ( $\mathrm{p}<$ 0,05) para a SH, o que permitiu variação positiva na massa corporal durante o experimento, suprindo as necessidades nutricionais em energia recomendadas pelo NRC (2007), estabelecida em $15 \mathrm{Mcal} /$ dia para a categoria animal utilizada (Tabela 4).

A preferência pela silagem de hemártria, mesmo com igual conteúdo de energia, sugere que essa variável comportamental está relacionada a outras particularidades do alimento, como o tamanho da partícula e a sensibilidade orossensorial dos cavalos. A preferência de cavalos por alimentos com maior conteúdo de energia também foi questionada por Martin-Rosset e Vermorel (1991), em experimento para identificar as necessidades diárias de energia. Murray (2004), ao ofertar silagem de alfafa para pôneis, salientou que a palatabilidade desse tipo de silagem foi fator determinante na preferência e no maior consumo desse alimento, a ponto de provocar obesidade nos animais. No presente estudo pode-se perceber que o mesmo ocorreu quando os animais foram alimentados com a silagem de hemártria. A adição de melaço e fubá pode ter influenciado na palatabilidade, aceitação e consumo dessa silagem. 0 melaço vem sendo acrescentado a alimentos concentrados comerciais por ser um alimento palatável aos equinos (NRC, 2007), além de poder ser utilizado na ensilagem como aditivo estimulador do consumo.

A silagem de hemártria apresentou menor percentual de material maior que $3,5 \mathrm{~cm}$ (Tabela 3), o que pode ter influenciado a preferência e o consumo, em razão da maior facilidade de apreensão e mastigação do alimento. Nagata (1971) relata que o consumo de alimentos pelos cavalos pode ser influenciado pelo tamanho e pela rigidez do alimento.
Argo et al. (2002), após utilizarem dietas totais, relataram que os animais alimentados com o mesmo alimento, sendo oferecido na forma peletizada, aumentam o consumo total da matéria seca.

No segundo ensaio deste trabalho, em estudo de livre escolha pelos animais, houve alto coeficiente de variação no tempo de ingestão, na quantidade e no percentual ingerido (Tabela 5), em virtude das características individuais das éguas. Pode-se observar que, apesar da possibilidade de escolha entre as silagens, as éguas também consumiram as silagens de milho e sorgo, identificadas como de menor preferência.

Müller e Udén (2007), em trabalho de preferência de equinos por forragens com diferentes meios de conservação, demonstraram que a silagem é a forma de conservação mais agradável aos animais, quando comparada aos fenos e pré-secados. A preferência por silagem identificada por esses autores e a grande variabilidade individual encontrada neste experimento indicam que os equinos apresentam sensibilidades orosensoriais próprias, as quais também determinam o comportamento individual de consumo de alimentos, identificadas também por Dulphy et al. (1997a, b).

\section{Conclusões}

O tempo destinado ao consumo das silagens de milho, hemártria e sorgo, por éguas da raça Mangalarga Marchador, é semelhante no período diário e entre os períodos do dia, independentemente da silagem consumida.

Os padrões comportamentais do tempo de consumo de silagens por equinos são equivalentes aos de cavalos em pastejo. 
Tabela 4 - Energia digestível estimada das silagens de milho, sorgo e hemártria por quilo de MS e consumo de energia digestível diária pelos animais

\begin{tabular}{lccc}
\hline Silagem & $\begin{array}{l}\text { Energia digestível estimada } \\
(\text { Mcal/kg) }\end{array}$ & $\begin{array}{l}\text { Energia digestível consumida } \\
\text { pelos animais em 24 horas } \\
\text { (Mcal/dia) }\end{array}$ & $\begin{array}{l}\text { Variação de massa corpórea dos } \\
\text { animais por período experimental } \\
\mathbf{( k g )}\end{array}$ \\
\hline Milho & $2,68^{\mathrm{a}}$ & $12,36^{\mathrm{b}}$ & $-15,52^{\mathrm{b}}$ \\
Sorgo & $2,73^{\mathrm{a}}$ & $13,75^{\mathrm{ab}}$ & $-0,72^{\mathrm{ab}}$ \\
Hemártria & $2,19^{\mathrm{b}}$ & $17,76^{\mathrm{a}}$ & $4,42^{\mathrm{a}}$ \\
\hline
\end{tabular}

Fonte: Dados da pesquisa.

Legenda: ${ }^{a} p<0,05$ vs ${ }^{b}$.

Tabela 5 - Tempo médio de consumo das silagens de milho, sorgo e hemártria, quantidade em quilos de cada tipo de alimento consumido e o percentual de consumo de cada alimento ofertado por um período de uma hora de avaliação

\begin{tabular}{|c|c|c|c|}
\hline Silagem & $\begin{array}{l}\text { Tempo médio de consumo } \\
\text { (uma hora de avaliação) }\end{array}$ & $\begin{array}{l}\text { Quantidade consumida durante } \\
\text { o período de uma hora }(\mathrm{kg})\end{array}$ & $\begin{array}{l}\text { Consumo de alimento ofertado } \\
\text { em uma hora de avaliação (\%) }\end{array}$ \\
\hline Milho & 19 minutos e 18 segundos $^{\text {ab }}$ & $0,46^{\mathrm{a}}$ & $22,8^{\mathrm{ab}}$ \\
\hline Sorgo & 7 minutos $^{b}$ & $0,25^{b}$ & $12,5^{b}$ \\
\hline Hemartria & 23 minutos e 42 segundos ${ }^{a}$ & $0,94^{\mathrm{a}}$ & $46,9^{\mathrm{a}}$ \\
\hline Coeficiente de Variação (\%) & 84,98 & 70,04 & 59,80 \\
\hline
\end{tabular}

Fonte: Dados da pesquisa.

Legenda: ${ }^{\text {a }} p<0,05$ vs ${ }^{\text {b. }}$

0 melaço adicionado à silagem indicou ter efeito palatabilizante ao estimular o consumo.

Silagem composta por partículas de menor tamanho possibilitam maior consumo no mesmo período de tempo.

A escolha da silagem a ser consumida também é influenciada pelo comportamento individual.

\section{Referências}

ARGO, C. M. G. et al. Adaptive changes in appetite, growth and feeding behavior of pony mares offered ad libitum access to a complete diet in either a pelleted or chaff-based form. Journal of Animal Science, v. 74, p. 517-528, 2002.

ASSOCIATION OF OFFICIAL ANALYTICAL CHEMISTS - AOAC. Official methods of analysis. 16th ed. Washington: AOAC, 1995.
BERGERO, D. et al. Intake and apparent digestibility of perennial ryegrass haylages fed to ponies either at maintenance or at work. Livestock Production Science, v. 77, p. 325-329, 2002.

CHANEY, A. L.; MARBACH, E. P. Modified reagents for determination of urea and ammonia. Clinical Chemistry, v. 8, p. $130-137,1962$.

DOMINGUES, J. L. Uso de volumosos conservados na alimentação de equinos. Revista Brasileira de Zootecnia, v. 38, p. 259-269, 2009. Suplemento.

DULPHY, J. P. et al. Compared feeding patterns in ad libitum intake of dry forages by horses and sheep. Livestock Production Science, v. 52, p. 49-56, 1997a.

DULPHY, J. P. et al. Evaluation of voluntary intake of forage trough-fed to light horses. Comparison with sheep. Livestock Production Science, v. 52, p. 97-104, 1997b. 
HANCHE-OLSEN, S. et al. Polyneuropathy associated with forage sources in Norwegian horses. Journal Veterinary Internal Medicine, v. 22, n. 1, p. 178-184, 2008.

KÖPPEN, W. P. Versuch einer Klassifikation der Klimate vorzugweise nach ihren Beziehungen zur Pflanzenwelt. Leipzig: B. G. Teubner, 1901.

LAMMES, B. P. et al. A simple method for the analysis of particle size of forage and total mixed rations. Journal of Dairy Science, v. 79, n. 5, p. 922-928, 1996.

LEWIS, L. D. Nutrição clínica equina: alimentação e cuidados. São Paulo: Rocca, 2000.

MARTIN, P.; BATESON, P. Measuring behaviour: an introductory guide. Cambridge: Cambridge University Press, 1986.

MARTIN-ROSSET, W.; VERMONEL, M. Maintenance energy requirements determined by indirect colorimetry and feeding trials in light horses. Journal Equine Veterinary Science, v. 11, p. 42-45, 1991.

MOORE-COLYER, M. J. S.; LONGLAND, A. C. Intakes and in vivo apparent digestibilites of four types of conserved grass forage by ponies. Journal Animal Science, n. 71, p. $527-534,2000$.

MORROW, H. J. et al. The apparent digestibilities and rates of passage of two chop-lengths of big-bale silage and hay in ponies, In: ANNUAL MEETING OF BRITISH SOCIETY OF ANIMAL SCIENCE, 1., 1999, New York. Proceedings... New York: British Society of Animal Science, 1999. p. 142. MÜLBACH, P. R. F. Silagem: produção com controle de perdas. In: LOBATO, J. F. P. et al. (Ed.). Produção de bovinos de corte. Porto Alegre: EDIPUCRS, 1999. p. 97-120.

MÜLLER, C. E.; UDÉN, P. Preference of horses for grass conserved as hay, haylage or silage. Animal Feed Science and Technology, v. 132, p. 66-78, 2007.

MURRAY, M. J. The effect of enzyme treatment and supplementary feedstuffs on the degradation of conserved forages by ponies. 2004. Tese (Doutorado em Zootecnia) - University of Wales, Aberystwyth, 2004.
NATIONAL RESEARCH COUNCIL - NRC. Nutrient requirements of horses. 6th ed. Washington: National, Academy of Sciences, 2007.

NAGATA, Y. Effects of various degrees of size and hardness of complete pelletized feed on feeding behavior of horses. Hokoku Exp. Reprod. Equine Health Labs, v. 1, n. 8, p. 72, 1971.

OLIVEIRA, K. et al. Trânsito gastrintestinal e digestibilidade aparente de nutrientes em equinos alimentados com dietas contendo grãos secos ou silagem de grãos úmidos de triticale. Revista Brasileira de Zootecnia, v. 36, p. 1799-1808, 2007.

PAGAN, J. D. et al. Exercise affects digestibility and rate of passage of an all forrage and mixed diets in Thoroughbred horses. Journal of Animal Nutrition, v. 128, p. 27042707, 1998.

SANTOS, C. P. et al. Avaliação da silagem de grãos úmidos de milho na alimentação de equinos em crescimento: valor nutricional e desempenho. Revista Brasileira de Zootecnia, v. 31, n. 3, p. 1214-1222, 2002.

SANTOS, E. M. et al. Comportamento ingestivo de equinos em pastagens de grama batatais (Paspalum notatum) e braquiarinha (Brachiaria decumbens) na região centro-oeste do Brasil. Revista Ciência Rural, v. 36, n. 5, p. 1565-1569, 2006.

VAN SOEST, P. J. Nutritional ecology of the ruminant. 2nd ed. Ithaca: Cornell University Press, 1994.

Recebido: 30/08/2011 Received: 08/30/2011

Aprovado: 11/11/2011 Approved: 11/11/2011 